\title{
Cloning, Expression and Purification of a Novel Multi-epitopic HIV-1 Vaccine Candidate: A Preliminary Study on Immunoreactivity
}

\author{
Samira Arabi ${ }^{1}$, Mohammad Reza Aghasadeghi ${ }^{2}$, Arash Memarnejadian ${ }^{2}$, Fatemeh Kohram ${ }^{3}$, \\ Haniyeh Aghababa ${ }^{4}$, Nima Khoramabadi ${ }^{4}$, Morteza Taghizadeh ${ }^{5}$, Zahra Shahosseini ${ }^{6}$, Mehdi Mahdavi ${ }^{6} *$ \\ 1 Department of Biology, Science and Research Branch, Islamic Azad University, Tehran, Iran \\ 2 Department of Hepatitis and AIDS, Pasteur Institute of Iran, Tehran, Iran \\ 3 Department of Biotechnology, Tehran Shargh Branch, Payam-e-Nour University, Tehran, Iran \\ 4 Department of Bacteriology, Faculty of Medical Sciences, Tarbiat Modares University \\ 5 Department of Medical virology, Tehran University of Medical Science, Tehran, Iran \\ 6 Department of Immunology, Pasteur Institute of Iran, Tehran, Iran.
}

Received Feb 3, 2014; Accepted May 20, 2014

\begin{abstract}
:
Introduction: Designing an effective vaccine against human immunodeficiency virus (HIV)-1 is a global health priority. Multiepitope vaccines offer several potential advantages that may be promising in case of mutable divergent pathogens such as HIV-1. Herein, a multiepitopic recombinant protein containing various HIV-1 antigens was expressed in E. coli cells and its immunogenicity in combination with different adjuvants was initially evaluated in BALB/c mouse. Methods: HIVtop4 sequence spanning the junction of six amino acid fragments $\left(\mathrm{Gag}_{158-186}, \mathrm{Pol}_{150-190}, \mathrm{ENV}_{296-323}, \mathrm{ENV}_{577-610}, \mathrm{Tat}_{1-20}\right.$ and $\left.\mathrm{Tat}_{44-61}\right)$ was designed based on immunoinformatic analysis to reduce the creation of junctional epitopes, improve the cleavage of proteasome and avoid the local accumulation of hydrophobic regions. Synthesized nucleotide sequence corresponding to HIVtop4 was cloned into pET23a plasmid. Expression of pET-HIVtop4 plasmid was induced in BL21 (DE3) E. coli cells by addition of $1 \mathrm{mM}$ IPTG during $3 \mathrm{~h}$ culture and the protein was purified by Ni-NTA column chromatography and further confirmed against anti-His antibody in western-blotting. Groups of BALB/c mice $(n=6)$ were immunized three times with 2 weeks interval, subcutaneously with $10 \mu \mathrm{g}$ of candidate vaccine adjuvanted in Complete Freund's adjuvant, Montanide ISA70 and Alum with suitable control groups. Two weeks after last immunization lymphocyte proliferation was measured with Brdu, IL-4 and IFN- $\gamma$ cytokines with ELISA, total antibody and IgG1, IgG2a isotypes with indirect ELISA methods. Results: Results showed that Immunization with HIV-1 tat/ pol/gag/env led to a significant increase in the proliferative responses of lymphocytes, IL- 4 and IFN- $\gamma$ cytokine production and humoral immune response in comparison with the control groups. Conclusion: In this study we concluded that Tat, Env, Pol, Gag with adjuvants (Montanide, Alum and CFA) has potentials as a candidate vaccine against the HIV-1 virus. Vac Res, 2014, 1 (1): 10-15
\end{abstract}

Keywords: HIV-1 tat/pol/gag/env, multi-epitope, Protein expression, Immune response.

\section{INTRODUCTION}

Development of an effective vaccine for prevention of AIDS has been a global health priority since the discovery of HIV-

*Corresponding Author: Mehdi Mahdavi

Department of Immunology, Pasteur Institute of Iran, Tehran, Iran.

No. 69, Pasteur Ave, Tehran, Iran, 1316943551.

Email: Mahdavivac@gmail.com

Tel/Fax: +98 2166496682
1 as the causative agent of the disease more than 3 decade ago which has caused infection in over 60 million people resulting in nearly 30 million deaths worldwide [1]. However, despite extensive efforts no safe and effective vaccine to prevent HIV-1 infection is available and the achievement of this goal has been hampered by the fact that the virus is highly variable resulting in its successful evasion of adaptive immune responses, broadly neutralizing antibodies are not induced, and a latent viral reservoir is established soon after the onset of infection $[1,2]$. To overcome these difficulties 
various candidate vaccines have been developed including whole inactivated virus, HIV-1 protein subunits and peptides epitopes, DNA vaccines, viral vectors expressing HIV antigens, therapeutic immunization and dendritic-cell-based vaccines [3].

Traditional vaccines use whole micro-organisms containing a large array of antigens which induce vast immunologic responses even though only a few are protective. Identification of these immunogenic epitopes has led to the production of vaccines incorporating only the critical epitopes in order to elicit the required immunologic response. However, due to the mammalian polyclonal immune response system, the rational approach is to include many immunogenic epitopes into a single vaccine $[4,5]$. These polyepitopic vaccines may induce strong immune responses against immunogenic and protective epitopes and thus may result in reduction of the number of vaccine administrations required [5].

Among the HIV-1 antigens Gag, Tat, Pol and Env have received considerable attention due to their critical roles in viral life cycle. The Gag protein is essential for HIV1 virus particle assembly [6]. The most important role of this protein is in the late stages of HIV replication, assembly, maturation and release of a mature viral particle [7]. Tat in the HIV-1 virus triggers apoptosis, hence, has a significant role in the pathogenesis of this virus and is the first known inhibitor of cytochrome $\mathrm{C}$ oxidase $(\mathrm{COX})$ activity $[8,9]$. The Pol gene codes for three enzymes; reverse transcriptase (RT), integrase and protease that are respectively responsible for amplification of viral genome, its integration into the host's genome and hydro- lyzing the precursor polypeptides into functional proteins. HIV-1 has been able to escape the effects of traditional vaccine preparations due to its antigenic variations. Thus, new vaccine development strategies must employ multiple epitopes from the HIV conserved immunogens [10]. In this study, we have used tat, env, pol and gag sequences based on their importance in the life cycle and pathogenesis of the virus as the selected targets. Following bioinformatic analysis of six immunogenic and conserved CTL epitopes, antigenic targets were selected and fused together. The recombinant protein corresponding to this polyepitopic sequence was expressed in E. coli BL-21 (DE3) to assess its immunogenicity in BALB/c mouse model.

\section{MATERIALS AND METHODS}

Construction of recombinant $\mathrm{HIV}-1$ tat/pol/gag/env expression vector. Searching through the Los Alamos HIV Molecular Immunology Database, six amino acid fragments identified as the regions containing HIV-1 CTL epitopes were selected from Tat, Env, Pol and Gag HIV-1 antigens (http:// www.hiv.lanl.gov/content/immunology/index.html). The six fragments (Table 1) were joined as a full length polytopic tandem of tat/pol/gag/env while three spacer sequences of AAY and AAA were designed at their junctions to firstly reduce the creation of junctional epitopes at the juxtaposition of two neighboring fragments and secondly to optimize the cleavage of the proteasome complex (Fig.1).

Table 1. Selected amino acid sequences of Tat, RT, P24 and Gp160 proteins from HIV-1 used in construction of the polyepitopic candidate vaccine

\begin{tabular}{|l|l|l|l|}
\hline Epitope & $\begin{array}{l}\text { Derived } \\
\text { From }\end{array}$ & $\begin{array}{c}\text { Residue } \\
\text { Numbers }\end{array}$ & \multicolumn{1}{c|}{ Amino Acid Sequence } \\
\hline Tat44 & Tat & $44-61$ & GISYGRKKRRQRRRAHQN \\
\hline Tat1 & Tat & $1-20$ & MEPVDPRLEPWKHPGSQPKT \\
\hline Pol150 & RT & $150-190$ & PQGWKGSPAIFQSSMTKILEPFRKQNPDIVIYQYMDDLYVG \\
\hline Gag158 & P24 & $158-186$ & KEPFRDYVDRFYKTLRAEQASQEVKNWMT \\
\hline Env577 & Gp160 & $577-610$ & QARILAVERYLKDQQLGIWGCSGKLICTTAVPW \\
\hline Env296 & Gp160 & $296-323$ & CTRPNNNTRKRIRIQRGPGRAFVTIGKI \\
\hline
\end{tabular}

\section{\begin{tabular}{ll|l|l|l|l} 
TAT AAY & POL & AAA & GAG & AAY & ENV \\
\hline
\end{tabular}}

Fig. 1. Schematic presentation of multi epitopic vaccine candidate comprising the sequences of Tat1-20 and Tat44-61, Pol150-190, Gag158-186, ENV296-323, ENV577-610, with AAY and AAA residues as spacer sequences interspersed between the epitopes. (AAY linker was included between Tat1-20 / Tat 44-61 and no linker was included between ENV296-323 / ENV 577-610).

Prediction of the optimal spacer fragments were performed using Rankpep (http://bio.dfci.harvard.edu/RAN-KPEP) and PaProc (http://paproc.de) software. To enhance the expression rate of the recombinant protein by minimizing the accumulation of hydrophobic residues in one region, protein analysis program in CLC Main Workbench 5.5 software was used. HIV-1 tat/pol/gag/env gene fragment was synthesized by Biomatik (Canada). The tat/pol/gag/env fragment was excised with Eco-RI/XhoI and sub-cloned into the same enzymatic sites in pET-23a expression vector and the construct was authenticated by enzymatic digestion and sequencing.

Expression and purification of recombinant HIV-1 tat/pol/ gag/env protein. Recombinant expression vector was transformed into E. coli BL21 (DE3) cells. A single transformant was cultured and induced for protein expression at mid-log phase $(\mathrm{OD} 600=0.5)$ for $3 \mathrm{~h}$ by addition of $1 \mathrm{mM}$ IPTG. His-tagged protein was purified in denatured condition using nickel-ni- 
trilotriacetic acid (Ni-NTA) affinity chromatography column (Qiagen, USA), according to the manufacturer's instructions. Briefly, expressing cells were resuspended in lysis buffer (100 $\mathrm{mM}$ NaH2PO4, $10 \mathrm{mM}$ Tris- $\mathrm{HCl}, 8 \mathrm{M}$ urea, $\mathrm{pH}=8$ ) by gentle vortexing and centrifuged for $10 \mathrm{~min}$ at $10^{\prime} 000 \mathrm{rpm}$. The obtained supernatant was loaded onto a Ni-NTA column after washing steps with wash buffer (100 mM NaH2PO4, $10 \mathrm{mM}$ Tris- $\mathrm{HCl}, 8 \mathrm{M}$ Urea, $\mathrm{pH}=6.4)$, fractions of pure protein were eluted in elution buffer (100 mM NaH2P04, 10 mM Tris-HCl, $8 \mathrm{M}$ urea, $\mathrm{pH}=4.5$ ). Identity and purity of the eluted protein was evaluated using SDS-PAGE and western blot with anti His-tag monoclonal antibody (Invitrogen, USA). The purified protein was quantified with Bradford method [11] and stored at $-20^{\circ} \mathrm{C}$ until use.

Animals. Six to eight-weeks old inbred female BALB/c mice were obtained from Pasteur Institute of Iran (Karaj, Iran). Mice were housed for one week before the experiments, given free access to food and water and were maintained in a light/dark cycle (12h/12h). All experiments were in accordance with the Animal Care and Use Protocol of Pasteur Institute of Iran.

Experimental groups and immunization. BALB/c mice were divided into seven groups $(n=6)$ and were immunized subcutaneously with $100 \mu$ of each formulation containing 20 $\mu \mathrm{g}$ of candidate vaccine adjuvanted in Complete Freund's (Sigma, USA), Montanide ISA70 (Seppic, France) and Alum adjuvants (Sigma, USA). Experimental groups were immunized three times with 2 weeks intervals. Control groups (Freund's, Montanide ISA70, Alum and PBS) were immunized under the same conditions. Two weeks after the last immunization, immunologic responses were assessed.

Lymphocyte proliferation assay. Two weeks after the final immunization, spleens were dissected from the mice and suspended in sterile cold PBS containing 2\% FBS. RBCs were lysed with lysis buffer and the single-cell suspension was adjusted to $2 \times 10^{6}$ cells/ml in RPMI 1640 (Gibco, Germany) supplemented with $10 \%$ FBS, $4 \mathrm{mM}$ L-glutamine, $1 \mathrm{mM}$ sodium pyruvate, $50 \mu \mathrm{m} 2 \mathrm{ME}, 100 \mu \mathrm{g} / \mathrm{ml}$ streptomycin and $100 \mathrm{IU} /$ $\mathrm{ml}$ penicillin. The cell suspension $(100 \mu \mathrm{l})$ was dispensed into a 96-well flat-bottom culture plate and stimulated with $10 \mu \mathrm{g} /$ $\mathrm{ml}$ of the recombinant protein as antigen recall. Phytohemagglutinin-A ( $5 \mu \mathrm{g} / \mathrm{ml}$, Gibco $)$ and un-stimulated wells were used as positive and negative controls, respectively and the culture medium was as blank. All experiments were done in triplicates. After $72 \mathrm{~h}$ of culture, $100 \mu \mathrm{l}$ of 5-bromo-2-deoxy-uridine $(\mathrm{Brdu})$ labeling solution was added to each well and the incubation was continued for $18 \mathrm{~h}$. The plates were then centrifuged and the culture medium was removed and $100 \mu \mathrm{l}$ of anti-Brdu antibody was added to each well. After washing the plates four times, tetramethylbenzidine solution was added as substrate and the reaction was stopped by adding $100 \mu 1$ of $2 \mathrm{~N}$ $\mathrm{H} 2 \mathrm{SO} 4$. Absorbance was measured using a spectrophotometric plate reader at $450 \mathrm{~nm}$. The stimulation index (SI) was calculated according to the formula: OD of stimulated wells/OD of un-stimulated wells.

IL-4 and IFN- $\boldsymbol{\gamma}$ cytokines ELISA. Two weeks after the final immunization, a total number of $4 \times 10^{6}$ splenocytes were seeded in a 24-well plate using a complete RPMI-1640 medium, stimulated in vitro with $10 \mu \mathrm{g} / \mathrm{ml}$ of recombinant protein and incubated at $37^{\circ} \mathrm{C}$ in $5 \% \mathrm{CO} 2$. Three days post antigen recall, supernatants were collected and centrifuged at $300 \mathrm{x}$ g for 10 min and stored at $-70^{\circ} \mathrm{C}$ for cytokine analysis. IFN- $\gamma$ and IL-4 cytokines were quantified using Quantikine ELISA Kit (R\&D Systems, USA) according to the manufacturer's instructions.

Measurement of total and IgG subclasses. Specific antibodies were determined by an optimized indirect ELISA method. Briefly, $100 \mu \mathrm{l}$ of $10 \mu \mathrm{g} / \mathrm{ml}$ of recombinant HIV-1 tat/pol/gag/ env protein in $50 \mathrm{mM}$ carbonate-bicarbonate buffer $(\mathrm{pH} 9.6)$ was added to 96-well ELISA Maxisorp plates (Nunc, Naperville, IL) and incubated for $24 \mathrm{~h}$ at $37^{\circ} \mathrm{C}$. Wells were washed with PBS containing $0.05 \%$ Tween 20 (TPBS) and blocked for $1 \mathrm{~h}$ at $37^{\circ} \mathrm{C}$ with $5 \%$ skimmed milk in PBS. After washing the plates with TPBS, $100 \mu 1$ of diluted sera (1/100 to $1 / 102400)$ were added to each well and the plate was incubated at $37^{\circ} \mathrm{C}$ for $2 \mathrm{~h}$. Wells were washed five times with TPBS and incubated for $2 \mathrm{~h}$ with $100 \mu \mathrm{l}$ of $1 / 8000$ dilution of HRP-conjugated anti mouse IgG (Sigma, USA). Plates were washed five times and incubated for $30 \mathrm{~min}$ with $100 \mu \mathrm{l}$ of TMB substrate in the dark and the reaction was stopped with $2 \mathrm{~N} \mathrm{H} 2 \mathrm{SO} 4$ and color intensity was measured at A450 nm with an ELISA plate reader. Detection of specific IgG1, IgG2a and IgM subclasses were carried out using goat anti mouse IgG1, IgG2a and IgM secondary antibodies (Sigma, USA) according to the manufacture's instruction.

Statistical analysis. All experiments were performed in triplicates and the data was expressed as means \pm SD of each experiment. Statistical analyses were carried out by one-way ANOVA and Tukey HSD test was used to compare the differences between the mean values of experimental groups using SPSS v18 software. $P$ values $<0.05$ were considered statistically significant.

\section{RESULTS}

Protein expression and purification. Induction of $E$. coli BL21 (DE3) cells harboring pET-HIVtop4 plasmid resulted in the expression of a protein of approximately $24 \mathrm{kDa}$ which was detected in bacterial lysate (Fig. 2A). The fusion protein was purified by Ni-NTA affinity chromatography and confirmed by anti-His monoclonal antibody by Western blotting.

Lymphocyte proliferation. The lymphocyte proliferation results showed that the candidate vaccine adjuvanted with Freund's, Montanide ISA70 and Alum increased lymphocyte proliferation compared with the control groups $(\mathrm{P} \leq 0.028)$. Although immunization of mice with vaccine candidate mixed with Freund's adjuvant increased the lymphocyte proliferation in comparison to Montanide ISA70 $(\mathrm{P}=0.04)$ and Alum $(\mathrm{P}=$ 0.03 ), this increase was not statistically significant (Fig. 3).

ELISA results of IL-4 and IFN- $\gamma$ cytokines production. Result of IL-4 cytokine assay showed that immunization with candidate vaccine adjuvanted with Freund's, Montanide ISA70 and Alum increased IL-4 cytokine compared with the control groups $(\mathrm{P} \leq 0.002)$. Immunization of mice with the vaccine candidate and Freund's adjuvant increased IL-4 cytokine in comparison to Montanide ISA70 $(\mathrm{P}=0.015)$ and Alum $(\mathrm{P}=0.105)$ but not significantly (Fig. 4). 


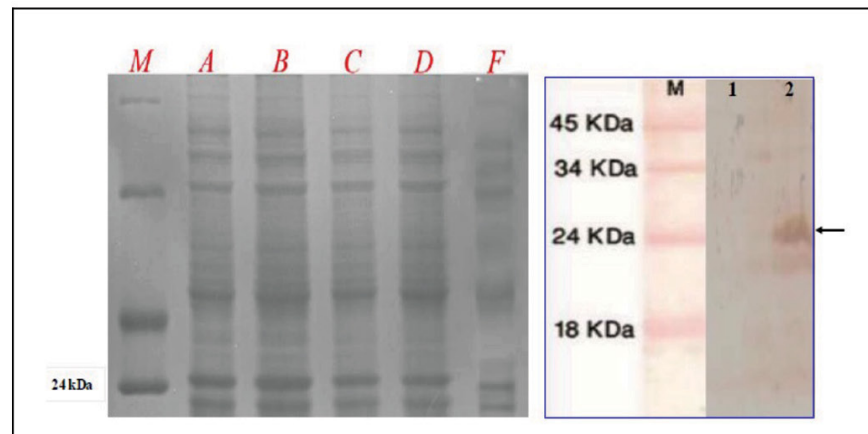

Fig. 2. SDS-PAGE and Western blot analysis of HIV-1 tat/pol/gag/env. A. Time course expression (1-4 h, lanes A-D) of the construct with $1 \mathrm{mM}$ IPTG: Lane M; marker, Lane F; un-induced bacteria. B. Western blot analysis of tat/pol/gag/env protein with anti-his antibody showing a band of approximately $24 \mathrm{kDa}$. Lane M; protein marker, Lane 1; uninduced bacteria, Lane 2; lysate from induced construct.

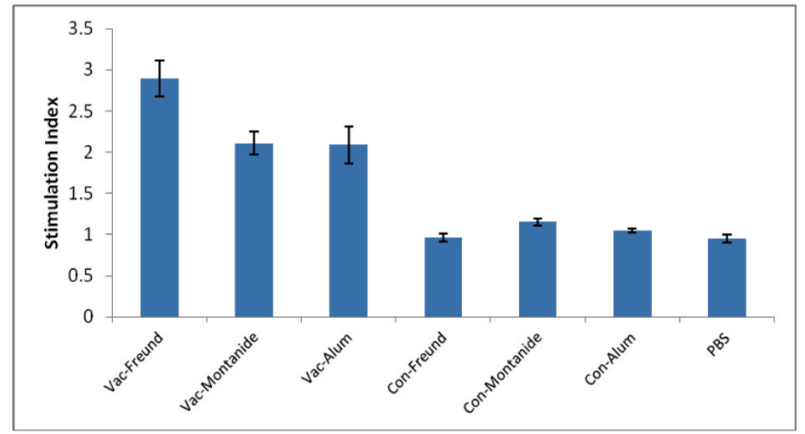

Fig. 3. Lymphocyte proliferation responses of the experimental groups after in vitro antigen recall. The stimulation indexes of the experimental groups are shown as mean \pm SD for 6 experiments.

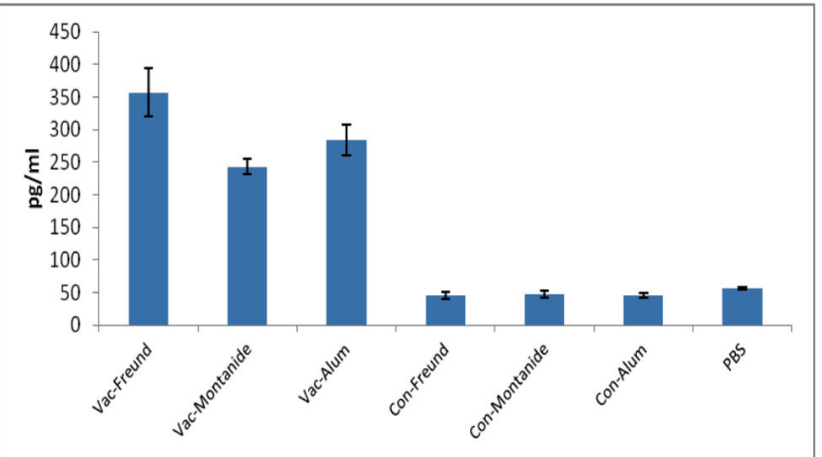

Fig. 4. In vitro stimulation with $\mathrm{HIV}$ tat/pol/gag/env protein showing significant increases in IL-4 production in the experimental groups after compared to the controls $p<0.002$ ).

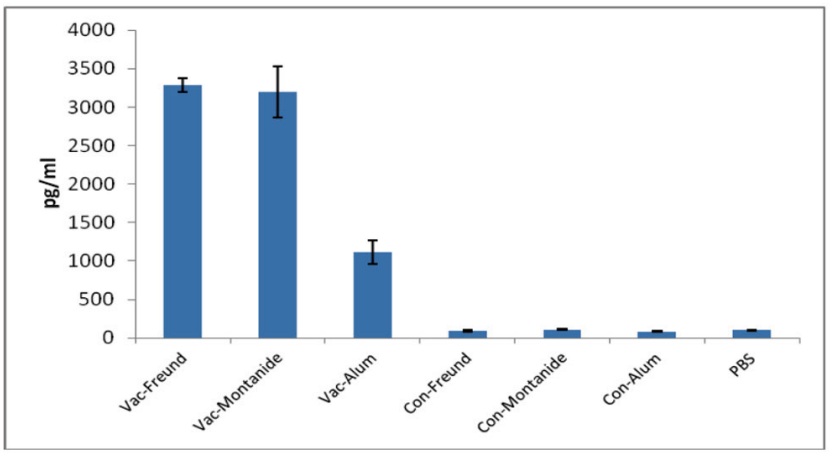

Fig. 5. IFN- $\gamma$ response of the experimental groups after in vitro stimulation with $\mathrm{HIV}$ tat/pol/gag/env protein compared to the control groups $(p<0.005)$. Immunization with Freund's and Montanide-adjuvanted recombinant protein raised higher levels of IFN- $\gamma$ compared to the Alum immunized group $(\mathrm{P}<0.014)$.

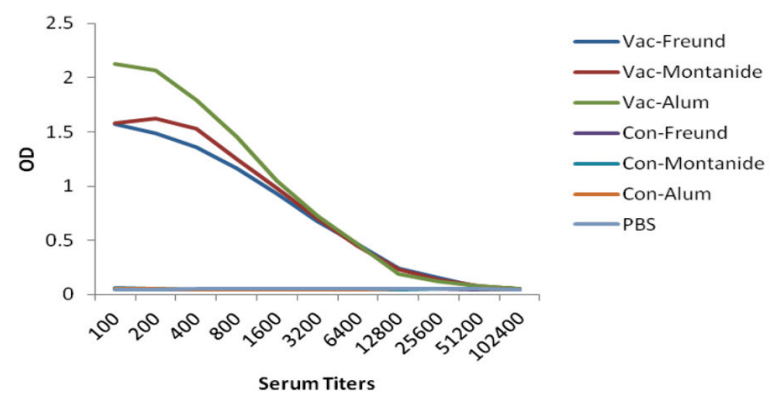

Fig. 6. Humoral immune responses of mice after immunization with the candidate vaccine showing that the adjuvanted recombinant protein increased total antibodies compared to the control groups $(\mathrm{P}<0.041)$. Immunization with Alum adjuvant at dilutions of $1 / 100$ and $1 / 200$ increased the total antibody response in comparison to Montanide and Freund's adjuvants $(\mathrm{P}<0.0021)$.

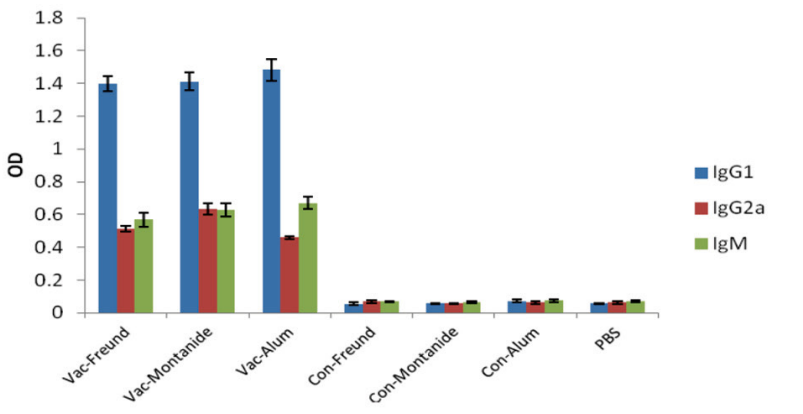

Fig. 7. Detection of specific IgG1, IgG2a and IgM isotypes in sera of mice evaluated by indirect ELISA. Data are presented as mean of triplicate experiments $\pm \mathrm{SD}$ of specific $\operatorname{IgG} 1, \operatorname{IgG} 2 \mathrm{a}$ and $\operatorname{IgM}$ for the experimental groups. Induction of specific IgG1 ( $\mathrm{P}<0.0001)$, $\operatorname{IgG} 2 \mathrm{a}(\mathrm{P}<0.0001)$ and $\operatorname{IgM}(\mathrm{P}<0.002)$ was significantly higher in the immunized groups compared to the controls.
Also there was not a statistically significant difference between IL-4 response using Montanide ISA70 or Alum $(\mathrm{P}=0.272)$.

IFN- $\gamma$ cytokine was also increased in response to the candidate vaccine adjuvanted with Freund's, Montanide ISA70 and Alum compared to the control groups $(\mathrm{P} \leq 0$
005; Fig. 5). Freund's adjuvant increased IFN- $\gamma$ cytokine in comparison to the Alum-adjuvanted group $(\mathrm{P}=0.0001)$ but not the Montanide ISA-70-adjuvanted group $(\mathrm{P}=1)$. IFN- $\gamma$ cytokine response in Montanide ISA-70 adjuvanted group was significantly higher in comparison to the Alum-adjuvanted groups $(\mathrm{P}=0.014)$. There were no significant differ- 
ences between the control groups $(\mathrm{P}=0.146)$.

Total Antibody measurement. Results of total antibodies responses showed that immunization with the candidate vaccine adjuvanted with Freund's, Montanide ISA70 and Alumadjuvant groups increased the total antibodies compared to the control groups (for $1 / 100$ to $1 / 51200 ; \mathrm{P} \leq 0.041$; Fig. 6).

Specific IgG1, IgG2a and IgM Isotypes determination. Immunization of mice with the candidate vaccine adjuvanted with Freund's, Montanide ISA70 and Alum increased IgG1, IgG2a and IgM isotypes (Fig.7) compared to the control groups $(\mathrm{P}<0.0001, \mathrm{P}<0.0001$ and $\mathrm{P}<0.002$, respectively). There was no significant difference between the adjuvants in the induction of $\operatorname{IgG} 1$ isotype antibody $(\mathrm{P}=0.935$ and $\mathrm{P}=$ 0.977 , respectively). IgG2a assay showed that the vaccine candidate adjuvanted in Montanide ISA70 significantly increased IgG2a level compared to Alum and Freund's ( $\mathrm{P}=$ 0.024 and $\mathrm{P}=0.037$, respectively), but no significant difference in the induction of specific IgM responses was observed between the immunized groups $(\mathrm{P}=0.581)$.

\section{DISCUSSION}

Constructing an immunogen composed of various HIV-1 viral epitopes that have key roles in the pathogenesis of HIV-1 could lead to development of an effective vaccine [12]. In the present study, we have designed a polyepitope candidate vaccine for HIV-1 which is based on proteins coded by tat, pol, gag and env genes that are conserved and can bind to a range of human and mouse MHCs and also to T-cell, B-cell, T-helper and T-cytotoxic receptors. Another consideration in selecting these proteins was their important roles in the viral cells cycle such as construction of the virus core [13], attachment to CD4 receptors on T-lymphocytes [14], replication of the virus [13] and increasing viral transcription [15].

Therefore, immunological responses against these combined epitopes in a vaccine candidate which could attack the virus from several points might result in a more effective vaccine. After immunization of the mice with the fusion protein, cellular and humoral immune responses were evaluated. Results of the lymphocyte proliferation assays showed that the vaccine candidate has been able to induce proliferative responses by all three adjuvants, namely Alum, Freund's and Montanide; however, the strongest proliferative responses were observed when Freund's adjuvant was used.

Proliferative responses are a symbol of the cellular immune responses [16] and considering the importance of the cellular immune responses in controlling viral infections, this could be considered as one of the advantages of this candidate vaccine.

Study of Reed et al. [17] showed that administration of a multi-epitope vaccine consisted of genes coding for Gag, Tat, Rev and Nef proteins caused an elevation in the cellular immune responses which was effective in controlling the viral replication.

Our previous study had also shown that a multi-epitope fusion protein based on Nef and P24 of HIV-1 could induce lymphocyte proliferation [12]. The results of IFN- $\gamma$ cytokine showed that all the three above-mentioned adjuvants induced IFN- $\gamma$, but better responses were observed in the Freund's immunized group.

The IFN- $\gamma$ cytokine is an indicative of Th 1 cellular immune responses and the induction of TCD $8+$ cells that have a key role in control and elimination of viral infections [18]. Many studies have shown the importance of IFN- $\gamma$ in the control of viral infection [19]. Ullum et al. [20] have measured the amount of IFN- $\gamma$ in healthy, HIV-infected and AIDS patients and have shown that a decrease in IFN- $\gamma$ was significantly correlated with progression to AIDS. Emu et al. [21] have also shown that IFN- $\gamma$ levels were highly correlated with HIV control in patients with HIV-1 viremia.

Our data indicated that our candidate vaccine has been able to increase IFN- $\gamma$ levels and has been able to induce a branch of the immune responses which has a key role in controlling viral infections. The results of IL-4 assessment as a Th2 cytokine showed stimulation of IL-4 production with all the adjuvants used. It has been shown that the production of this cytokine has a significant effect on the function of B cells and induction of the humoral immunity [22]. The antibody levels obtained indicated that our multiepitope fusion protein has been able to induce antibody responses with all three adjuvants used. Humoral responses are highly important in neutralizing viruses and for prevention of viral infections [23-27]. Given that an increase in $\operatorname{IgG} 1$ indicates Th1 induction and $\operatorname{IgG} 2 \mathrm{a}$ is an indicative of Th2 [28], it can be concluded that our candidate vaccine can stimulate both $\mathrm{Th} 1$ and $\mathrm{Th} 2$ responses. In addition, the results showed that our candidate vaccine injected with Alum, Freund's and Montanide adjuvants could induce specific IgM production. These results are in agreement with other studies indicating that polyepitope vaccines can induce vaccine specific IgM which is essential for controlling viral infections [29-31]. Moreover, all three adjuvants could induce different levels of humoral and cellular immune responses that indicate the effect of adjuvants on the vaccine immunogenicity.

\section{CONCLUTION}

The overall results of our study indicated that the candidate vaccine which we had prepared as a recombinant protein could significantly stimulate the cellular and humoral immune responses showing Thl shift and an increase in IFN- $\gamma$. However, further studies are required in order to define the exact effects of our candidate vaccine on the viral infection, its biological properties and its suitability for use in pre- and clinical trials.

\section{ACKNOWLEDGEMENTS}

This work was funded by grant No. 91004064 from Iran National Science Foundation (INSF) and grant no. 559 from Pasteur Institute of Iran. We gratefully acknowledge the help and technical support given us by Dr. Kayhan Azadmanesh and Dr. Mehdi Sadat.

\section{CONFLICT OF INTEREST}

The authors do not have any conflict of interests. 


\section{REFERENCES}

1. Barouch DH. Challenges in the development of an HIV-1 vaccine. Nature, 2008; 455 (7213): 613-9.

2. Karlsson Hedestam GB, Fouchier RA, Phogat S, Burton DR, Sodroski J, Wyatt RT. The challenges of eliciting neutralizing antibodies to HIV-1 and to influenza virus. Nat Rev Microbiol, 2008; 6 (2): 143-55.

3. Puls RL, Emery S. Therapeutic vaccination against HIV: current progress and future possibilities. Clin Sci (Lond), 2006; 110 (1): 5971.

4. Smith SG. The polyepitope approach to DNA vaccination. Curr Opin Mol Ther, 1999; 1 (1): 10-5.

5. Baird M, Wilson R, Young L, Williman J, Young S, Wilson M, Slobbe L, Lockhart E, Buchan G. Bystander help within a polyepitope DNA vaccine improves immune responses to influenza antigens. Scand J Immunol, 2004; 60 (4): 363-71.

6. Waheed AA, Freed EO. HIV type $1 \mathrm{Gag}$ as a target for antiviral therapy. AIDS Res Hum Retroviruses, 2012; 28 (1): 54-75.

7. Changela A, Wu X, Yang Y, Zhang B, Zhu J, Nardone GA, O'Dell S, Pancera M, Gorny MK, Phogat S, Robinson JE, Stamatatos L, Zolla-Pazner S, Mascola JR, Kwong PD. Crystal structure of human antibody 2909 reveals conserved features of quaternary structure-specific antibodies that potently neutralize HIV-1. J Virol, 2011; 85 (6): 2524 35 .

8. Zhang SM, Song M, Yang TY, Fan R, Liu XD, Zhou PK. HIV-1 Tat impairs cell cycle control by targeting the Tip60, Plk1 and cyclin B1 ternary complex. Cell Cycle, 2012; 11 (6): 1217-34.

9. Lecoeur H, Borgne-Sanchez A, Chaloin O, El-Khoury R, Brabant M, Langonne A, Porceddu M, Briere JJ, Buron N, Rebouillat D, Pechoux C, Deniaud A, et al. HIV-1 Tat protein directly induces mitochondrial membrane permeabilization and inactivates cytochrome c oxidase. Cell Death Dis, 2012; 3: e282.

10. Haynes BF, Kelsoe G, Harrison SC, Kepler TB. B-cell-lineage immunogen design in vaccine development with HIV-1 as a case study. Nat Biotechnol, 2012; 30 (5): 423-33.

11. Faezi S, Safarloo M, Amirmozafari N, Nikokar I, Siadat SD, Holder IA, Mahdavi M. Protective efficacy of Pseudomonas aeruginosa type-A flagellin in the murine burn wound model of infection. APMIS, 2014; 122 (2):115-27

12. Mahdavi M, Ebtekar M, Azadmanesh K, Khorramkhorshid HR, Rahbarizadeh F, Yazdi MH, Zabihollahi R, Abolhassani M, Hassan ZM. HIV-1 Gag p24-Nef fusion peptide induces cellular and humoral immune response in a mouse model. Acta Virol, 2010; 54 (2): 131-6.

13. Hoshikawa N, Kojima A, Yasuda A, Takayashiki E, Masuko S, Chiba J, Sata T, Kurata T. Role of the gag and pol genes of human immunodeficiency virus in the morphogenesis and maturation of retrovirus-like particles expressed by recombinant vaccinia virus: an ultrastructural study. J Gen Virol, 1991; 72 ( Pt 10): 2509-17.

14. Dalgleish AG, Beverley PC, Clapham PR, Crawford DH, Greaves MF, Weiss RA. The CD4 (T4) antigen is an essential component of the receptor for the AIDS retrovirus. Nature, 1984; 312 (5996): 763-7.

15. Debaisieux S, Rayne F, Yezid H, Beaumelle B. The ins and outs of HIV-1 Tat. Traffic, 2012; 13 (3): 355-63.

16. Fakharzadeh S, Kalanaky S, Hafizi M, Goya MM, Masoumi Z, Namaki S, Shakeri N, Abbasi M, Mahdavi M, Nazaran MH. The new nano-complex, Hep-c, improves the immunogenicity of the hepatitis B vaccine. Vaccine, 2013; 31 (22): 2591-7.

17. Wilson NA, Reed J, Napoe GS, Piaskowski S, A. Szymanski, Furlott J, Gonzalez EJ, Yant LJ, Maness NJ, May GE, Soma T, Reynolds $\mathrm{MR}$, et al. Vaccine-induced cellular immune responses reduce plasma viral concentrations after repeated low-dose challenge with pathogenic simian immunodeficiency virus SIVmac239. J Virol, 2006; 80 (12): 5875-85.

18. Mahdavi M, Ebtekar M, Khorram Khorshid HR, Azadmanesh K, Hartoonian C, Hassan ZM. ELISPOT analysis of a new CTL based DNA vaccine for HIV-1 using GM-CSF in DNA prime/peptide boost strategy: GM-CSF induced long-lived memory responses. Immunol Lett, 2011; 140 (1-2): 14-20.

19. Jamali A, Mahdavi M, Hassan ZM, Sabahi F, Farsani MJ, Bamdad T, Soleimanjahi H, Motazakker M, Shahabi S. A novel adjuvant, the general opioid antagonist naloxone, elicits a robust cellular immune response for a DNA vaccine. Int Immunol, 2009; 21 (3): 217-25.

20. Ullum H, Cozzi Lepri A, Bendtzen K, Victor J, Gotzsche PC, Phillips AN, Skinhoj P, Klarlund Pedersen B. Low production of interferon gamma is related to disease progression in HIV infection: evidence from a cohort of 347 HIV-infected individuals. AIDS Res Hum Retroviruses, 1997; 13 (12): 1039-46.

21. Emu B, Sinclair E, Favre D, Moretto WJ, Hsue P, Hoh R, Martin JN, Nixon DF, McCune JM, Deeks SG. Phenotypic, functional, and kinetic parameters associated with apparent T-cell control of human immunodeficiency virus replication in individuals with and without antiretroviral treatment. J Virol, 2005; 79 (22): 14169-78.

22. Burstein HJ, Tepper RI, Leder P, Abbas AK. Humoral immune functions in IL-4 transgenic mice. J Immunol, 1991; 147 (9): 2950-6.

23. LoBue AD, Thompson JM, Lindesmith L, Johnston RE, Baric RS. Alphavirus-adjuvanted norovirus-like particle vaccines: heterologous, humoral, and mucosal immune responses protect against murine norovirus challenge. J Virol, 2009; 83 (7): 3212-27.

24. Tarr AW, Urbanowicz RA, Ball JK. The role of humoral innate immunity in hepatitis C virus infection. Viruses, 2012; 4 (1): 1-27.

25. Rossi CP, Cash E, Aubert C, Coutinho A. Role of the humoral immune response in resistance to Theiler's virus infection. J Virol, 1991; 65 (7): 3895-9.

26. Vauloup-Fellous C, Grangeot-Keros L. Humoral immune response after primary rubella virus infection and after vaccination. Clin Vaccine Immunol, 2007; 14 (5): 644-7.

27. Aspbury AS, Gabor CR. Discriminating males alter sperm production between species. Proc Natl Acad Sci U S A, 2004; 101 (45): 15970-3.

28. Bhattacharya M, Neogi SB. Estimation of mortality due to AIDS--a review. Indian J Public Health, 2008; 52 (1): 21-7.

29. Kim CY, Kang ES, Kim SB, Kim HE, Choi JH, Lee DS, Im SJ, Yang $\mathrm{SH}$, Sung YC, Kim BM, Kim BG. Increased in vivo immunological potency of HB-110, a novel therapeutic HBV DNA vaccine, by electroporation. Exp Mol Med, 2008; 40 (6): 669-76.

30. Ferrantelli F, Maggiorella MT, Schiavoni I, Sernicola L, Olivieri E, Farcomeni S, Pavone-Cossut MR, Moretti S, Belli R, Collacchi B, Srivastava IK, Titti F. A combination HIV vaccine based on Tat and Env proteins was immunogenic and protected macaques from mucosal SHIV challenge in a pilot study. Vaccine, 2011; 29 (16): 2918-32.

31. Melchers M, Bontjer I, Tong T, Chung NP, Klasse PJ, Eggink D, Montefiori DC, Gentile M, Cerutti A, Olson WC, Berkhout B, Binley JM. Targeting HIV-1 envelope glycoprotein trimers to B cells by using APRIL improves antibody responses. J Virol, 2012; 86 (5): 2488-500. 